\title{
ESTUDO DE PLANEJAMENTO E DESIGN DE UM MÓDULO INSTRUCIONAL SOBRE O SISTEMA RESPIRATÓRIO: O ENSINO DE CIÊNCIAS PARA SURDOS
}

\section{Study planning and design of an instructional module about the respiratory system: the science education of the deaf}

\author{
Thanis Gracie Borges Queiroz ${ }^{1}$ • Diego França Silva ${ }^{2}$. \\ Karlla Gonçalves de Macedo ${ }^{3}$ • Anna Maria Canavarro Benite ${ }^{4}$
}

\begin{abstract}
Resumo: Discorremos sobre o estudo do planejamento e design de um módulo instrucional para o ensino de ciências, especificamente para o ensino do sistema respiratório para alunos surdos. Primeiramente, apresentamos uma discussão sobre a educação de surdos pautada por questões linguísticas, que envolvem o ensino da língua portuguesa e a língua de sinais. Descrevemos a estratégia de criação do módulo, que está pautada no sociointeracionismo, e, finalmente, descrevemos uma situação de intervenção pedagógica analisando o processo de apropriação conceitual. Para tanto, apresentamos episódios de aulas para o $8^{\circ}$ ano do Ensino Fundamental da Associação dos Surdos de Goiânia. Constituíram o design do módulo diferentes formas de representação do conhecimento científico. Nossos resultados permitem inferir que a estratégia foi utilizada como ferramenta da ação mediada e como instrumento de explicação e previsão. Ainda, permitiu aos alunos perceberem, estabelecerem relações e conhecerem fenômenos naturais simbolizados a partir das sequências vivenciadas.
\end{abstract}

Palavras-chave: Ensino de ciências. Educação de surdos. Módulo instrucional. Linguagem.

\begin{abstract}
This research presents the planning and design of an instructional module for teaching science, more specifically of the respiratory system for teaching deaf students. First, we address a discussion on deaf education based on linguistic issues, which involves the teaching of Portuguese and sign languages. We describe the strategy of creating a module that is based on social interactionism, and finally describe a situation of educational intervention by analyzing the process of conceptual appropriation. Therefore, we present episodes occurring in class 8th grade elementary school of the Association of the Deaf Goiânia (ASG), with the participation of nine students. The module design uses different forms of representation of scientific knowledge. Our results infer that the strategy was used as a tool of action and not as mediated reality, a tool of explanation and prediction. It allowed the students to perceive, build relationships and learn from the natural phenomena symbolized in the sequences experienced.
\end{abstract}

Keywords: Science teaching. Education of the deaf. Instructional module. Language.

${ }^{1-4}$ Laboratório de Pesquisas em Educação Química e Inclusão, Instituto de Química, Universidade Federal de Goiás (UFG). Campus II, Samambaia, Rodovia Goiânia-Nerópolis, Caixa postal 131. Goiânia, GO, Brasil.

74.000-970.thanisqueiroz@hotmail.com 


\section{Sobre a educação de surdos}

Historicamente, a educação de surdos esteve voltada para questões linguísticas, em específico, para a discussão do ensino do português (oral e/ou escrito) e do uso da língua de sinais (QUADROS, 2004).

Marco deste processo foi a proibição das línguas de sinais no Congresso de Milão, em 1880, o que, segundo muitos autores (LACERDA, 1998; LOPES, 2007; SKLIAR, 2006; QUADROS, 2005), comprometeu bruscamente a educação dos surdos, impedindo a possibilidade do desenvolvimento escolar efetivo desses indivíduos (QUEIROZ; BENITE, 2010).

Em contraponto, Quadros (2004, p. 55) alerta sobre a opinião dos profissionais de instituições escolares que atendem surdos:

Os profissionais não acreditam que por meio da língua de sinais seja, de fato, possível discutir os avanços científicos e tecnológicos que cabem à escola trabalhar. Assim, delega-se à escrita o papel de assumir tal função. Mais uma vez, perpassa-se a sobreposição do português (língua da maioria) à língua de sinais, como aconteceu ao longo da história da educação de surdos.

Neste contexto, durante anos, alguns grupos de surdos e estudiosos da educação desses sujeitos lutaram pela liberação da língua de sinais, mas só agora a sociedade escolar começa a reconhecer sua importância para o desenvolvimento das potencialidades da cultura surda (KARNOPP, 2004). Esse processo acontece de forma lenta e sua evolução pode ser descrita por três abordagens: oralismo, comunicação total e bilinguismo. De maneira sucinta, cabe retratar cada uma dessas filosofias educacionais da história da educação dos surdos, devido ao seu preponderante papel na atual situação linguística desses sujeitos.

A filosofia oralista adota uma postura com ênfase na visão clínica, com o objetivo de reabilitar o surdo em busca da normatização, afirmando que só a fala possibilita a integração do surdo à vida social (GOLDFELD, 2002).

A comunicação total surge na tentativa de reverter o quadro de baixos rendimentos no desempenho cognitivo dos alunos a partir do desenvolvimento da linguagem oral, recorrendo a: gestos naturais, leitura orofacial, uso constante de aparelhos de amplificação sonora, alfabeto digital, escrita, expressão facial, bimodalismo ${ }^{5}$ linguagem oral, ou seja, qualquer artifício que facilite a comunicação (PEREIRA, 2008).

Embora a comunicação total tenha sido a principal divulgadora da língua de sinais por trazer os sinais usados pela comunidade surda em sua proposta metodológica -, não apresentou relevância ao papel dessa língua na construção de uma segunda língua, no caso do Brasil, o português (MACHADO, 2008), e, sim, artificializando a comunicação, perdendo de vista as implicações sociais da surdez, reduzindo, assim, o uso de sinais ao papel de um recur-

\footnotetext{
${ }^{5}$ Bimodalismo significa duas línguas sendo utilizadas simultaneamente por uma pessoa, neste caso, as línguas envolvidas são: a língua portuguesa em sua modalidade oral e a língua brasileira de sinais (CICCONE, 1990). 
so de ensino que apoia a fala. Existindo, neste caso, um ajuste da língua de sinais à estrutura da língua portuguesa (ALMEIDA, 2000).

Por assumir que a língua de sinais deve ser a primeira língua (L1) dos sujeitos em questão, enquanto a língua do grupo social majoritário, na sua modalidade escrita, deverá ser aprendida como segunda língua (L2), o bilinguismo - filosofia proposta pela Declaração de Salamanca (DECLARAÇÃO..., 1994) - atualmente, tem sido considerado, por vários autores, como a abordagem que melhor atende às necessidades educativas dos surdos.

Hoje, a lei no 10.436, de 24 de abril de 2002 (BRASIL, 2002) e o decreto $n^{\circ} 5.626$, de 22 de dezembro de 2005 (BRASIL, 2005), que a regulamenta, reconhecem a língua brasileira de sinais - Libras - como língua de uso corrente e legítimo de uma grande parcela de surdos brasileiros, além de sua inserção e de sua regulamentação nos currículos de Ensino Básico para surdos nas escolas inclusivas.

Uma das considerações mais importantes do modelo de educação bilíngue do surdo é a presença de uma comunidade com cultura e língua próprias que, na escola, reivindica melhores condições para seu ensino, com a presença do professor surdo ou de um intérprete em sala de aula e com materiais e metodologias voltados à sua realidade (QUEIROZ, 2010).

Urge a necessidade de uma mudança pedagógica, é preciso mudar o foco no trabalho com os surdos, e esse trabalho deve ser centrado no desenvolvimento da linguagem, mas que não se resuma apenas à introdução da língua de sinais na escola (QUEIROZ et al., 2010). Concordamos com Reily (2003) quando menciona que é necessário que as escolas organizem o currículo partindo de uma perspectiva visual/espacial; e, se o processo educacional ocorre mediante a interação linguística, deve ocorrer, portanto, na língua brasileira de sinais juntamente com outras experiências visuais, tais como língua portuguesa escrita, mímica/dramatização, figuras, recursos tecnológicos (vídeo/TV, slides, computador, retroprojetor) e leitura, desenvolvendo, nos alunos, a memória visual e o hábito de leitura; recebendo apoio de professor especialista conhecedor de língua de sinais, além de proporcionar intérpretes de Libras, para o maior acompanhamento das aulas.

Defendemos que outro instrumento bastante peculiar que pode compor a ação mediada de ensino para surdos é o módulo instrucional, que consiste num material de apoio, para auxílio ao estudante no processo de interpretação do discurso do sistema oficial de ensino (SOUZA, 2010; AXT, 1991).

Sob a ótica da Educação Inclusiva, deparamo-nos com o avanço tecnológico da sociedade, que há tempos preconiza uma dependência em relação às ciências. Os Parâmetros Curriculares Nacionais (BRASIL, 1999), por sua vez, defendem a importância de se ensinar ciências desde os anos iniciais de escolarização, assumindo que:

Num mundo onde o saber científico e tecnológico é cada dia mais valorizado, é impossível a formação de um cidadão crítico e apto a realizar escolhas, tanto em nível pessoal quanto social e político sem os conhecimentos básicos necessários para a realização de julgamentos e consequentes opções. (BENITE et al., 2009, p. 3)

Além disto, a Educação Brasileira está fundamentada no princípio da igualdade: "do reconhecimento dos direitos humanos e o exercício dos direitos e deveres da cidadania" (BRA- 
Queiroz, T. G. B. et al.

SIL, 1998, p. 8). Considerando que a cidadania se refere à participação efetiva dos indivíduos, tenham eles necessidades educacionais especiais ou não, em todas as esferas da sociedade, torna-se evidente a necessidade do ensino de ciências. Deve-se ensinar Ciências para permitir ao cidadão ser protagonista do mundo em que vive.

Vale ressaltar que poucos são os estudos sobre o ensino de ciências para surdos (FELTRINI; GAUCHE, 2007; MACHADO, 2003; LEMOS NETO et al., 2007); e, em relação ao ensino de ciências propriamente dito, Maldaner e Zanon (2001) afirmam que o módulo instrucional permite uma abordagem com característica interdisciplinar, articulando as vivências dos alunos - seus conhecimentos cotidianos - com os saberes e conteúdos científicos. Já Chassot (2003, p. 23) considera que, "ser alfabetizado cientificamente é saber ler a linguagem em que está escrita a natureza". Aquele que não consegue realizar uma leitura do universo é considerado analfabeto científico.

Para além destas questões, está a sala de aula de ciências, com sua linguagem socialmente negociada e simbólica, de maneira que, como professores de ciências, objetivamos, neste trabalho, apresentar estudos sobre o planejamento e desenvolvimento de um módulo instrucional que foi utilizado como estratégia de ensino e aprendizagem numa turma de alunos surdos, e avaliar a apropriação conceitual mediante a utilização desta ferramenta na ação mediada.

\section{Sobre a opção metodológica}

Os saberes científicos circulam, entre outras esferas, na escola, organização social de formato particular: aprendizagem orientada. A escola, por sua vez, privilegia atividades onde "a forma de interação escrita, adapta a linguagem científica, produzindo gêneros específicos próprios" (SOUZA, 2010, p. 50). A produção das atividades escolares, geralmente, é precedida pela interação verbal entre professores e alunos e conduzida pelas intervenções do professor no desenvolver do conteúdo temático. Essa prática é chamada de "ouvintismo" (SKLIAR, 1997, 1998) e traduz uma pedagogia delimitada pela onipresença da língua oficial e pela separação entre escola e alunos surdos.

De mesmo modo, apoiamo-nos em Neves (2007, p. 119) para afirmar que existem duas formas de se armazenar o conhecimento: "a lingüística (semântica), que inclui fala e leitura; e não lingüística, que inclui imagens mentais e até mesmo sentidos físicos, como olfato, audição, tato etc". Assumidos estes pressupostos, entendemos que a preparação de material que circula na esfera escolar, ou seja, os gêneros do discurso escolar-científico (material instrucional) envolvem mais que escrita orientada por interação verbal. É fundamental que estes permitam ao alunado que expresse o pensamento claro sobre o entendimento dos princípios conceituais científicos.

Com base nessas características, desenvolvemos um material instrucional para ser utilizado por alunos surdos na aprendizagem de ciências, associado, entretanto, ao discurso do sistema oficial de ensino e de recursos que possam privilegiar a cultura surda.

Uma professora de ciências em formação continuada e dois professores de química em formação inicial, orientados por uma professora formadora, planejaram e desenvolveram módulos instrucionais sobre a temática "Corpo Humano", e, neste trabalho, será apresentado 
o extrato referente ao "Sistema Respiratório". Para a construção deste módulo, os autores se reuniram durante todo o ano letivo de 2009 (encontros semanais de duas horas de duração gravados em áudio e vídeo) e fundamentaram a construção em contribuições da comunidade científica sobre: a educação de surdos, a língua de sinais, estratégias de ensino e aprendizagem, além de discussões sobre conceitos específicos do tema corpo humano (SANTOS, 2005; SELLES; AYRES, 2009). Foram etapas de realização deste trabalho:

1. Eleição do tema do material instrucional, e os critérios que delimitaram a escolha foram: importância social, abrangência conceitual e potencialidade de dialogar com conhecimentos aprendidos em outras disciplinas.

2. Elaboração da estrutura constitutiva do módulo e determinação da dinâmica de trabalho com o mesmo.

Além da revisão da literatura específica, a pesquisa bibliográfica foi realizada em sítios eletrônicos que disponibilizam imagens com boa resolução, tais como tirinhas em quadrinhos e material digital reprodutível. Como parte integrante do módulo, foi elaborado um jogo de cartas baseado no trabalho desenvolvido no Projeto Fundão de Biologia da Universidade Federal do Rio de Janeiro (MATTOS et al., 2007).

Confeccionados os módulos instrucionais, estes foram utilizados como estratégias pedagógicas em uma escola cuja entidade mantenedora é a Associação dos Surdos de Goiânia, numa turma de $8^{a}$ ano do Ensino Fundamental, turma essa formada por educandos (em sua maioria) surdos e/ou deficientes auditivos que não tiveram acesso à escolarização na idade própria ou não se desenvolveram no mesmo ritmo na rede regular de ensino.

Os módulos foram utilizados, durante um semestre, por um dos autores desta investigação, que é professor em formação continuada (e intérprete de Libras) na língua portuguesa em sua modalidade oral; porém, os intérpretes atuantes na instituição também realizaram as interpretações dessa linguagem para a língua de sinais. As intervenções pedagógicas foram gravadas em áudio e vídeo, posteriormente transcritas e analisadas, bem como as atividades realizadas pelos alunos.

Este trabalho se caracteriza como uma pesquisa participante, com um enfoque de investigação social, por meio da qual se busca a participação da comunidade na análise de sua própria realidade, com o objetivo de promover ações coletivas para o benefício da comunidade escolar. Trata-se, portanto, de uma atividade educativa de investigação e ação social (BRANDÃO, 1984).

\section{Resultados e discussões}

Em se tratando de materiais didáticos englobando estratégias de ensino para alunos surdos, nos deparamos com uma vasta escassez, e a alternativa para os professores desses sujeitos é construírem seus próprios materiais. Para isso, é necessário que estes profissionais "façam levantamentos das tendências e preferências dos alunos para que melhor se possa conhecer os estilos e estratégias de cada aluno no caminho da construção do conhecimento" (SILVA; NEMBRI, 2008, p. 55), refletindo sobre os objetivos do ensino de ciências e sobre o seu papel dentro da perspectiva da Educação Inclusiva. Esse, então, foi o caminho por nós escolhido. 
Queiroz, T. G. B. et al.

Privilegiamos as sensações físicas, como olfato, tato e associação sinestésica, por assumirmos que as representações não linguísticas podem ser complementares às representações linguísticas no processo de aprendizagem, e, portanto, sua utilização por professores deve ser motivada.

$\mathrm{Na}$ construção do módulo instrucional, com o intuito de estudar o funcionamento do sistema respiratório no organismo humano, levou-se em consideração o uso da língua de sinais - Libras - como a primeira língua (L1) do sujeito surdo, e a língua portuguesa em sua modalidade escrita como a segunda língua (L2), além de diversos recursos de estímulos visuais. Em momentos distintos, cada uma dessas estratégias foi empregada separadamente e, em outras ocasiões, interligadas. O módulo foi desenvolvido para ser realizado em cinco aulas, com duração de quarenta minutos cada, discriminado detalhadamente nos Quadros 1, 2 e 3.

O Decreto no 5.626 (BRASIL, 2005) considera como línguas a serem utilizadas durante todo o processo educativo dos estudantes surdos, fazendo referência à filosofia educacional bilíngue adotada pela instituição pesquisada: a modalidade escrita da Língua Portuguesa e a Libras. Assim sendo, todas as atividades propostas no módulo envolveram essas duas línguas.

Durante anos, os surdos têm sido vistos como maus leitores, sobretudo devido à dificuldade que apresentam na compreensão de textos escritos. Porém, de um modo geral, os surdos não apresentam dificuldades para decodificar símbolos gráficos, e, desta maneira, privilegiamos, na confecção deste material, tal utilização.

$\mathrm{Na}$ primeira etapa descrita no Quadro 1, os alunos deveriam realizar a leitura na língua portuguesa escrita presente na tirinha em quadrinhos, assim como escrever suas conclusões sobre o tema explicitado na mesma, e, posteriormente, relatá-las em Libras. Notou-se que os alunos realizaram a leitura individual, mas encontraram dificuldades na compreensão da história como unidade, sendo necessária a interferência da professora lendo o texto proposto e sendo interpretada pelo profissional intérprete presente na sala de aula.

A intervenção consistiu em um roteiro de leitura, antecipando desconhecidas palavras e expressões fundamentais para o entendimento do texto, chamando a atenção, também, para os aspectos materiais, como as ilustrações, favorecendo a associação entre linguagem não verbal e verbal.

Após essa intervenção, a compreensão do texto pelos educandos aparentemente ainda se encontrava confusa, devido aos seus relatos escritos. Porém, ao citarem suas conclusões utilizando a Libras, foi possível perceber maior compreensão do conteúdo relatado na tirinha em quadrinhos, tal como as narrativas a seguir. 
Estudo de planejamento e design de um módulo ...

Quadro 1. Descrição das atividades desenvolvidas no módulo instrucional para o tema Sistema Respiratório

\begin{tabular}{|c|c|}
\hline & $1^{\text {a }}$ ETAPA \\
\hline Tempo necessário & 02 aulas de 40 minutos \\
\hline Desenvolvimento & $\begin{array}{l}\text { 1. Cada aluno recebeu uma tirinha em quadrinhos que ironiza o costume das } \\
\text { pessoas de respirarem um ar poluído encontrado nas grandes cidades. } \\
\text { Figura 1. Tirinha em quadrinhos } \\
\text { ALINE - Adáo Iturrusgarai } \\
\text { Figura 2. Pôster esquemático do sistema respiratório } \\
\text { Fonte: Queiroz (2011) }\end{array}$ \\
\hline Objetivos & $\begin{array}{l}\text { Interpretação da tirinha em quadrinhos, relacionando com a realidade da } \\
\text { poluição nas cidades grandes; } \\
\text { Compreender a composição e o funcionamento do sistema. }\end{array}$ \\
\hline $\begin{array}{l}\text { Estratégia de avaliação } \\
\text { da apropriação } \\
\text { conceitual }\end{array}$ & $\begin{array}{l}\text { Após a leitura individual, os alunos compartilharam suas opiniões sobre a tirinha, } \\
\text { além de escrever sobre. (As opiniões em Libras foram transcritas para a atividade). }\end{array}$ \\
\hline
\end{tabular}


Queiroz, T. G. B. et al.

Quadro 1. Descrição das atividades desenvolvidas no módulo instrucional para o tema Sistema Respiratório

\begin{tabular}{|c|c|}
\hline \multicolumn{2}{|r|}{$2^{\mathrm{a}}$ ETAPA } \\
\hline Tempo necessário & 02 aulas de 40 minutos \\
\hline Desenvolvimento & $\begin{array}{l}\text { 1. Os alunos colaram um esquema do sistema respiratório no caderno após o } \\
\text { reconhecimento e identificação desse em uma cartela destacável com várias fotos } \\
\text { de outros diferentes sistemas. } \\
\text { Figura 3. Esquema do sistema respiratório } \\
\text { Fonte: Queiroz (2011) } \\
\text { 2. Foi relembrado o funcionamento do sistema respiratório, com exibição de um } \\
\text { envolvidas no processo desse sistema. } \\
\text { 3. Exposições em slides do funcionamento do diafragma, e como ocorre a } \\
\text { hematose, por meio da utilização de figuras, tal como as apresentadas nas figuras } \\
\text { 5, } 6 \text { e } 7 \text {. } \\
\text { 4. Atividade para os alunos descreverem os termos: } \\
\text { a) respiração } \\
\text { Figura 4. Relação do ambiente com o sistema respiratório }\end{array}$ \\
\hline
\end{tabular}


Estudo de planejamento e design de um módulo ...

Quadro 1. continuação

\begin{tabular}{|c|c|}
\hline Desenvolvimento & b) aparelho ou sistema respiratório \\
\hline Objetivos & $\begin{array}{l}\text { Compreender o funcionamento do diafragma e da hematose; } \\
\square \text { Verificar a aprendizagem de termos relacionados ao tema. }\end{array}$ \\
\hline Estratégia de avaliação & $\begin{array}{l}\text { Os alunos, utilizando língua portuguesa escrita, descreveram suas } \\
\text { compreensões sobre os esquemas propostos. }\end{array}$ \\
\hline
\end{tabular}


Queiroz, T. G. B. et al.

Quadro 3. Descrição das atividades desenvolvidas no módulo instrucional para o tema Sistema Respiratório: $3^{\mathrm{a}}$ etapa

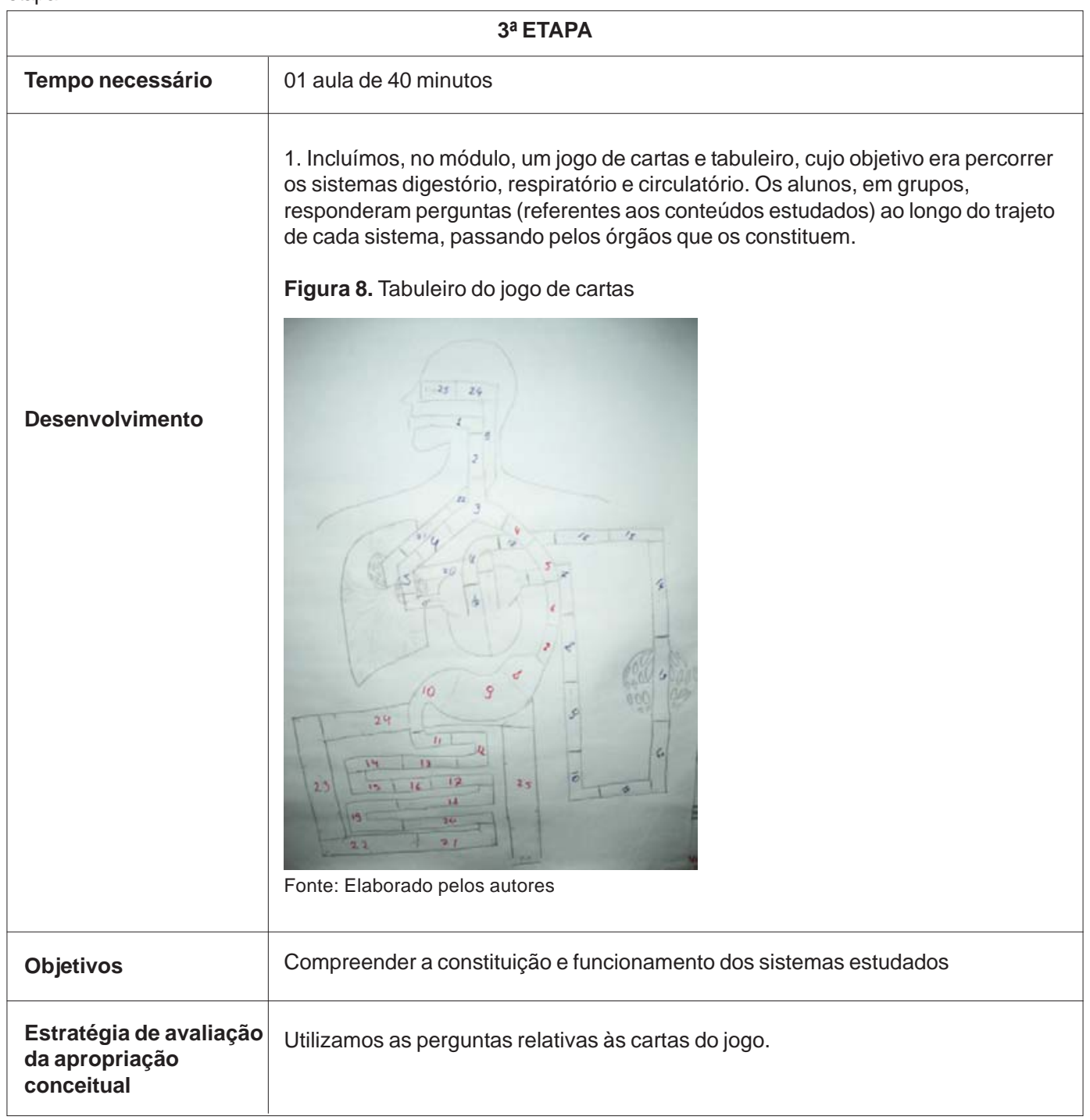

Figura 9. Cópia da resposta escrita pelo aluno A76 sobre o tema proposto pela tirinha em quadrinhos

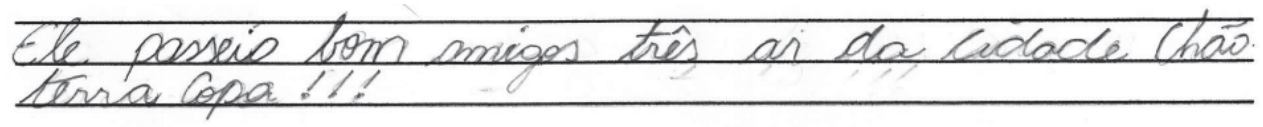
${ }^{6}$ Utilizamos A como referência aos alunos, seguido pela numeração correspondente a cada um dos
participantes. 
Estudo de planejamento e design de um módulo ...

Resposta de A7 em libras, interpretada para o português:

A7/I5: "São três pessoas passeando na floresta, parece uma roça. Está respirando uma fumaça, atchim, saúde. É bom pra saúde passear. O ar da floresta é muito melhor porque o da cidade não é bom pra saúde, faz mal pro pulmão"

Figura 10. Cópia de resposta escrita pelo aluno A9 sobre o tema proposto pela tirinha em quadrinhos

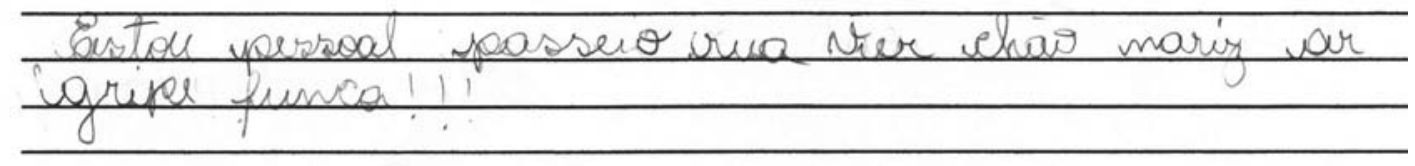

Resposta de A9 em libras, interpretada para o português:

A9/I5: "São três amigos que saíram, foram passear na floresta. Os amigos levaram mochila, levaram comida e saíram pela floresta. Acharam um lugar e disseram "Ah não... esse lugar não está bom" e foram pra outro lugar e montaram as coisas pra comer. O ar da floresta é melhor, bom pra saúde, o da cidade é ruim porque pode causar doença. A pessoa deixa a cidade pra morar no campo porque o ar do campo é melhor".

As narrativas de A7 e A9 permitem considerar que, como a maioria dos alunos, estes possuíam conhecimentos sobre o tema em língua de sinais, no entanto desconheciam expressões e palavras em português para designá-las, ocorrendo, assim, questionamentos de como escrevê-las. Podemos considerar que a leitura dos alunos foi realizada de maneira ideográfica, pela rota lexical, que, segundo Alpendre e Azevedo (2008, p. 16), significa "reconhecimento visual das palavras que serão fotografadas e memorizadas no dicionário mental, se a elas corresponder alguma significação".

Esses sujeitos vivem em uma sociedade cuja linguagem predominante é a língua portuguesa, portanto faz-se necessário que possuam um bom domínio dessa língua em sua modalidade escrita; por isso, os estímulos para leitura e escrita devem ser constantes, mesmo que essa ferramenta seja considerada um desafio para os sujeitos dessa investigação, precisando ser contextualizada a partir da Libras, sendo esta língua capaz de melhorar a construção de novos conhecimentos.

\footnotetext{
${ }^{7}$ Utilizamos I como referência ao intérprete, seguido pela numeração correspondente a cada um dos participantes. A fala do aluno foi interpretada pela intérprete da língua de sinais-língua portuguesa. 
Queiroz, T. G. B. et al.

Por outro lado, não desconsiderando que a leitura envolve a decodificação de símbolos gráficos, a compreensão de um texto se faz não só por informações textuais, mas, pelas contextuais internas e externas do próprio texto. Nossos resultados apontam que a intervenção do professor permitiu ao surdo leitor reconstruir algum significado do texto com base não só em seu conhecimento de mundo, mas com as intenções e elementos linguísticos usados pelo autor.

A língua de sinais inscreve-se no lugar da visualidade por se caracterizar como uma linguagem visoespacial, facilitando o despertar para a atenção e para a memória visual. Importante ressaltar que todas as aulas foram ministradas na linguagem oral, porém interpretadas em língua de sinais.

A utilização da Libras demonstrou ter conseguido maior acesso ao processo de significação conceitual nas aulas de Ciências, já que permitiu, aos surdos, exposição mais detalhada e estruturada dos conceitos apreendidos.

Como segundo ponto norteador para a confecção do módulo, destacou-se a visão como eixo central nas atividades propostas. Enfocando os recursos visuais como facilitadores no processo de ensino e aprendizagem, corroboramos com outros estudos (REILY, 2003; QUEIROZ; BENITE, 2009) que destacaram a importância do uso desses, permitindo estabelecer relações entre o conhecimento científico e o senso comum, ressaltadas nos exemplos a seguir.

Figura 11. Cópia da descrição sobre o tema "respiração" pelo aluno A7

1. Descreva sobre os seguintes termos:

a) Respiraçăo:

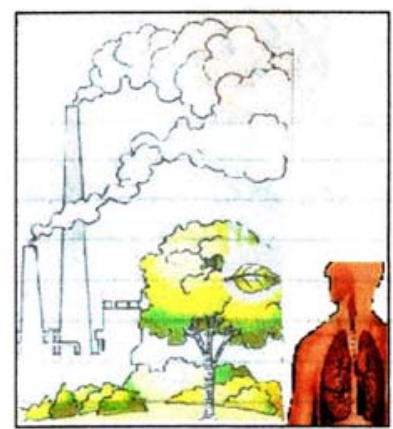

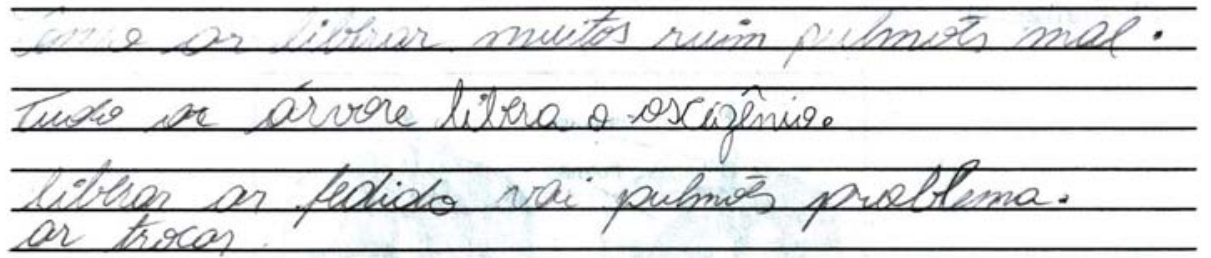


Estudo de planejamento e design de um módulo ...

Figura 12. Cópia da descrição sobre o tema "sistema respiratório" pelo aluno A7

\section{b) Aparelho respiratório ou Sistema respiratório:}

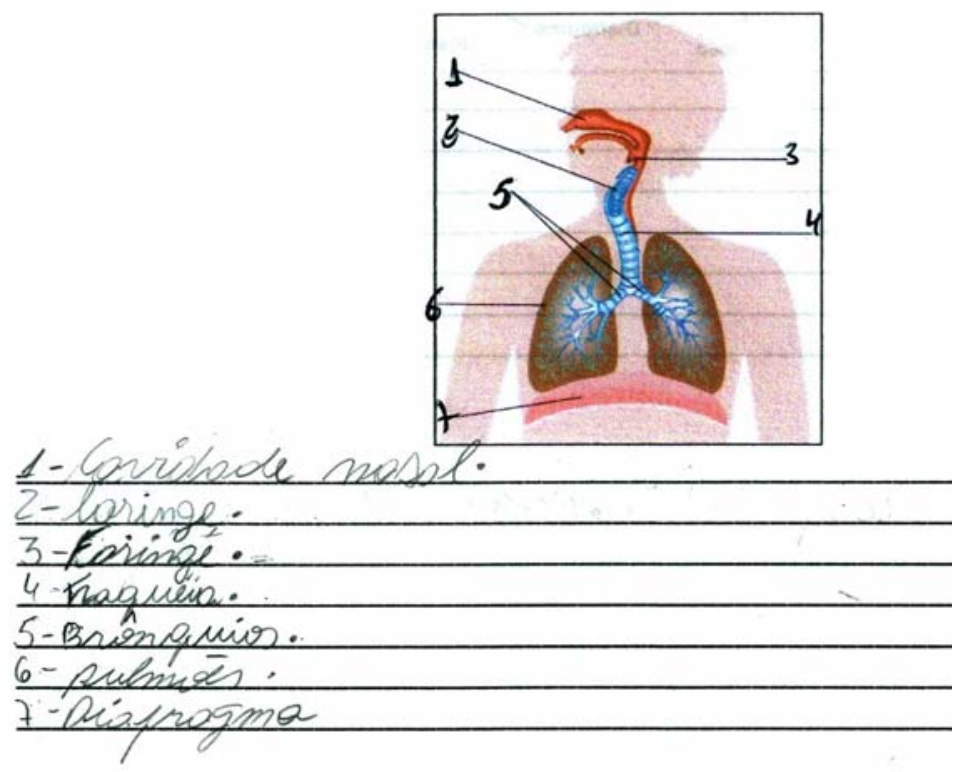

Figura 13. Cópia da descrição sobre o tema "hematose" pela aluna A2

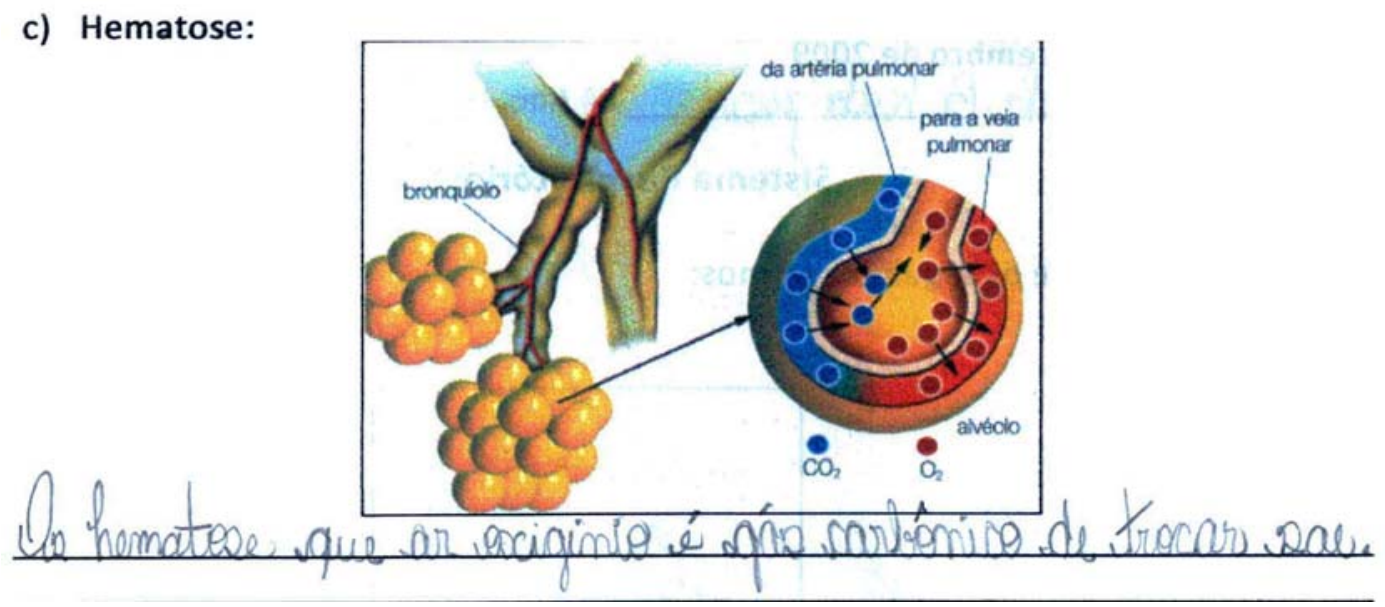


Queiroz, T. G. B. et al.

Figura 14. Cópia da descrição sobre o tema "hematose" pela aluna A1

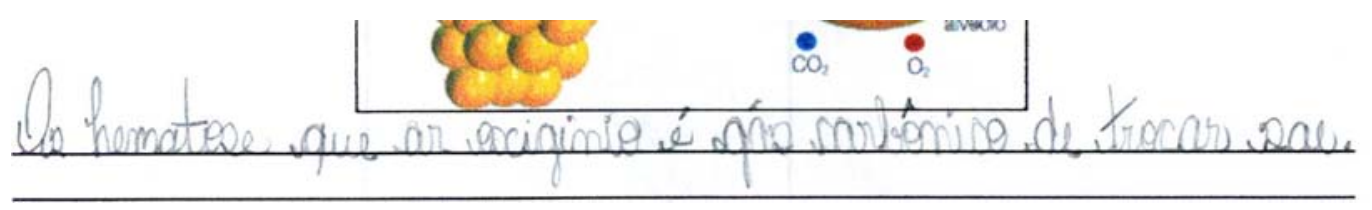

Figura 15. Cópia da descrição sobre o tema "diafragma" pelo aluno A4

d) Diafragma:

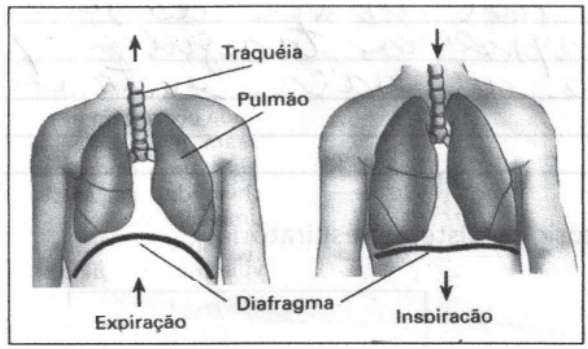

encher esrerziar

Cabe destacar uma comparação entre a sintaxe da Libras e do português, que têm estruturas lexicais diferentes e não correspondentes, por exemplo: duas ou mais palavras em português podem ser expressas por um sinal.

Nossos resultados permitem inferir que maior desenvolvimento da aprendizagem parece ser alcançado se a linguagem escrita for utilizada em conjunto com outras ferramentas de apelo visual (como vídeos, pôsteres, jogos, apresentação de figuras), funcionando como instruções, pistas para uma melhor compreensão do conteúdo.

Em todas as atividades, estavam presentes recursos visuais, dentre eles: história em quadrinhos, vídeos, slides com figuras, esquemas do sistema respiratório em forma de pôster, em folha A4 e do tabuleiro do jogo, conforme se pôde observar na descrição do módulo instrucional no Quadro 1.

Para os autores, esta iniciativa representou uma experiência inédita de elaboração de material didático, e sua utilização mostrou - por meio dos resultados de sua utilização com os alunos - que pode ser uma opção viável para o ensino de ciências para surdos. A utilização do módulo gerou interesse ao longo das aulas, que se manifestou pela participação ativa dos alunos na realização das atividades proposta no módulo, tais como apresentamos em nossos resultados. E, consequentemente, gerou uma interação entre professores e alunos.

Envolver professores formadores, em formação inicial e em formação continuada, na elaboração de um material didático, representou uma experiência de reflexão sobre: os objetivos do ensino de ciências para surdos, sobre o papel do professor nessa elaboração e sobre a relevância dos conteúdos a serem ministrados nas aulas de ciências. 
Estudo de planejamento e design de um módulo ...

\section{Conclusões}

Com o objetivo de permitir que um conjunto de competências fosse alcançado pelos estudantes, planejamos o módulo instrucional, ou seja, um conjugado de atividades de aprendizagem, cuja vantagem em seu uso é o fato de permitir que os professores desenvolvam vários exemplos e utilizem aqueles que melhor satisfaçam suas necessidades, implantando-os de maneira gradual e sem necessidade de reorganização do programa de ensino.

Em se tratado de surdez, foi de extrema seriedade percebermos a importância da língua de sinais e dos recursos visuais como recursos metodológicos para elaboração do material de apoio no processo de ensino e aprendizagem, pois a informação linguística, nessa língua, é recebida pelo sistema visual humano.

O módulo instrucional permitiu ao professor organizar as aulas, buscando que este instrumento fosse um reforço para a atenção e compreensão do educando, facilitando, assim, a sua aprendizagem. Para tal, dois pontos foram considerados norteadores nesse processo: (a) utilização da língua portuguesa em sua modalidade escrita, envolvendo a leitura e a própria escrita, e a língua de sinais; e (b) o sentido da visão como eixo central.

\section{Agradecimentos \\ À FAPEG, ao CNPq e à ASG.}

\section{Referências}

ALMEIDA, E. O. C. de. Leitura e surdez: um estudo com adultos não oralizados. Rio de Janeiro: Revinter, 2000.

ALPENDRE, E. V.; AZEVEDO, H. J. S. Concepções sobre surdez e linguagem e a aprendizagem de leitura. Curitiba: SEED, 2008.

AXT, R. Considerações sobre produção e disseminação de material instrucional (para ensino de ciências). Caderno Brasileiro de Ensino de Física, Florianópolis, v. 8, n. 1, p. 14-19, 1991.

BENITE, A. M. C. et al. Formação de professores de ciências em rede social: uma perspectiva dialógica na educação inclusiva. Revista Brasileira de Pesquisa em Educação em Ciências, Belo Horizonte, v. 9, n. 3, p. 1-21, 2009.

BRANDÃO, C. R. Pesquisa participante. 2. ed. São Paulo: Brasiliense, 1984.

BRASIL. Decreto-lei no 5.626, de 22 de dezembro de 2005. Regulamenta a lei $\mathrm{n}^{\circ} 10.436$, de 24 de abril de 2002, e o art. 18 da lei no 10.098, de 19 de dezembro de 2000. Diário Oficial [da] República Federativa do Brasil, Poder Executivo, Brasília, DF, 23 dez. 2005. Seção 1, p. 28. 
Queiroz, T. G. B. et al.

BRASIL. Lei n ${ }^{\circ}$ 10.436, de 24 de abril de 2002. Dispõe sobre a língua brasileira de sinais Libras e dá outras providências. Diário Oficial [da] República Federativa do Brasil, Poder Legislativo, Brasília, DF, 25 abr. 2002. Seção 1, p. 23.

. Ministério da Educação. Secretaria de Educação Média e Tecnológica. Parâmetros Curriculares Nacionais: Ensino Médio. Brasília, 1999.

. Constituição (1988). Constituição da República Federativa do Brasil. Brasília: Senado Federal, 1998.

CHASSOT, A. Alfabetização científica: uma possibilidade para a inclusão social. Revista Brasileira de Educação, Rio de Janeiro, n. 22, p. 89-100, jan./abr. 2003.

CICCONE, M. M. C. Comunicação total: introdução, estratégia a pessoa surda. Rio de Janeiro: Cultura Médica, 1990.

DECLARAÇÃO de Salamanca e linha de ação sobre necessidades educativas especiais. Brasília: CORDE, 1994.

FELTRINI, G. M; GAUCHE, R. Ensino de ciências a estudantes surdos: pressupostos e desafios. In: ENCONTRO NACIONAL DE PESQUISA EM EDUCAÇÃO EM CIÊNCIAS, 6., 2007, Florianópolis. Anais... Florianópolis: ABRAPEC, 2007. p. 1-11.

GOLDFELD, M. A criança surda: linguagem e cognição numa perspectiva sociointeracionista. 2. ed. São Paulo: Plexus, 2002.

KARNOPP, L. B. Língua de sinais na educação dos surdos. In: THOMA, A. S.; LOPES, M. C. (Org.). A invenção da surdez: cultura, alteridade, identidade e diferença no campo da educação. Santa Cruz do Sul: Edunisc, 2004.

LACERDA, C. B. F. de. Um pouco da história das diferentes abordagens na educação dos surdos. Cadernos Cedes, Campinas, v.19, n. 46, p. 68-80, 1998.

LEMOS NETO, L. et al. O ensino de química e a aprendizagem de alunos surdos: uma interação mediada pela visão. In: ENCONTRO NACIONAL DE PESQUISA EM EDUCAÇÃO EM CIÊNCIAS, 6., 2007. Anais... Belo Horizonte: Associação Brasileira de Pesquisa em Educação em Ciências, 2007. v. 1. p. 1-12.

LOPES, M. C. Surdez \& educação. Belo Horizonte: Autêntica, 2007.

MACHADO, P. C. A política educacional de integração/inclusão: um olhar do egresso surdo. Florianópolis: Ed. da UFSC, 2008.

A mediação da aprendizagem do surdo através da informática: CD-ROM de biologia. São José, SC: [s.n.], 2003.

MALDANER, O. A.; ZANON, L. B. Situação de estudo: uma organização de ensino que extrapola a formação disciplinar em ciências. Espaços da Escola, Ijú, v. 41, p. 45-60, 2001. 
Estudo de planejamento e design de um módulo ...

MATTOS, R. et al. Jogo: aventura das moléculas. Rio de Janeiro: UFRJ, 2007. Disponível em: <http://www.projetofundao.ufrj.br/biologia/images/materiais/

jogo_aventura_das_moleculas_aline_navarro_suelen.pdf>. Acesso em: 17 nov. 2009.

NEVES, D. A. B. Meta-aprendizagem e ciência da informação: uma reflexão sobre o ato de aprender a aprender. Perspectivas em Ciência da Informação, Belo Horizonte, v. 12, n. 3, p.116-128, 2007.

PEREIRA, R. de C. Surdez: aquisição de linguagem e inclusão social. Rio de Janeiro: Revinter, 2008.

QUADROS, R. M. Educação de surdos: efeitos de modalidade e práticas pedagógicas. In: MENDES, E. G.; ALMEIDA, M. A.; WILLIAMS, L. C. de A. (Org.). Temas em educação especial IV. São Carlos: EdUFSCar, 2004. p. 55-61.

. Alternativas de formações profissionais no campo da surdez. In: CONGRESSO

INTERNACIONAL DE SURDEZ, 8., 2005, Rio de Janeiro. Anais... Rio de Janeiro: INES, 2005. p. 44-48.

QUEIROZ, T. G. B. Estudos de planejamento e design de material instrucional: o ensino de ciências para surdos. 2011. 114 f. Dissertação (Mestrado em Educação em Ciências e Matemática) - Universidade Federal de Goiás, Goiânia, 2011.

. Bilinguismo na educação do surdo: conhecimentos do professor. In: ENCONTRO NACIONAL DE DIDÁTICA E PRÁTICA DE ENSINO, 15., 2010, Belo Horizonte. Anais... Belo Horizonte: UFMG, 2010. 1 CD-ROM.

QUEIROZ, T. G. B.; BENITE, A. M. C. Ensino de ciências e surdez: esse "outro" na sala de aula. Revista da SBEnBIO, Campinas, v. 3, p. 698-709, out. 2010. 1 CD-ROM.

A educação de surdos mediada pela língua de sinais e outras formas de comunicação visual. In CONGRESSO NACIONAL DE EDUCAÇÃO, 25., 2009, Goiânia. Anais... Goiânia: UFG, 2009.

QUEIROZ, T. G. B. et al. Ensino de ciências/química e surdez: o direito de ser diferente na escola. In: ENCONTRO NACIONAL DE ENSINO DE QUÍMICA, 15., 2010, Brasília. Anais... Brasília: UnB, 2010. Disponível em: <http://www.xveneq2010.unb.br/resumos/ R0737-1.pdf>. Acesso em: 12 nov. 2010.

REILY, L. H. As imagens: o lúdico e o absurdo no ensino de arte para pré-escolares surdos. In: SILVA, I. R., KAUCHAKJE, S., GESUELI, Z. M. (Org.). Cidadania, surdez e linguagem: desafios e realidades. São Paulo: Plexus Editora, 2003. p. 161-192.

SANTOS, M. A. dos. Biologia educacional. São Paulo: Ática, 2005. (Série Educação).

SELLES, S. E; AYRES, A. C. M. O ensino de respiração humana na formação inicial de professores: questões para um debate. In: TEIXEIRA, P. M. M.; RAZERA, J. C. C. (Org.). Ensino de ciências: pesquisa e pontos em discussão. Campinas: Komedi, 2009. p. 47-66.

SILVA, A. C. da.; NEMBRI, A. G. Ouvindo o silêncio: educação, linguagem e surdez. Porto Alegre: Mediação, 2008. 
Queiroz, T. G. B. et al.

SILVA, R. A. Sistema respiratório. 2007. 1 fotografia.

SKLIAR, C. (Org.). Educação e exclusão. 5. ed. Porto Alegre: Mediação, 1997.

SKLIAR, C. A surdez: um olhar sobre as diferenças. Porto Alegre: Mediação, 1998.

A inclusão que é "nossa" e a diferença que é do outro. In: RODRIGUES, D.

Inclusão e educação: doze olhares sobre a educação inclusiva. São Paulo: Summus, 2006. p. 15-34.

SOUZA, D. D. Sobre a mediação de um material instrucional na aprendizagem de estudantes em aulas de química: gêneros do discurso e argumento. 2010. 140 f. Tese (Doutorado em Educação) - Faculdade de Educação, Universidade de São Paulo, São Paulo, 2010.

Artigo recebido em 17/06/11. Aceito em 29/03/2012. 